\title{
Eating habits associated with body weight gain in UK university students
}

\author{
E. F. Sprake ${ }^{1}$, J. Lavin ${ }^{2}$, J. M. Russel1 ${ }^{3}$, P. Grabowski ${ }^{1}$ and M. Barker ${ }^{1}$ \\ ${ }^{1}$ Human Nutrition Unit, The Medical School, University of Sheffield, S10 2RX, UK, ${ }^{2}$ Slimming World, Alfreton, \\ Derbyshire, DE55 4RF, UK and ${ }^{3}$ Corporate Information \& Computing Services, University of Sheffield, S10 $2 F N, U K$
}

The first year of university life has been identified as a period associated with body weight gain ${ }^{(1,2)}$. However, little is currently known about the reasons for this weight gain ${ }^{(1,2)}$. This study examined eating habits and physical activity levels among university students in the UK in relation to body weight gain.

University student members of Slimming World in the UK completed an online survey about their weight gain, eating habits and physical activity levels at university prior to joining Slimming World. Chi-Square tests were employed to examine factors associated with four categories of self-reported weight gain at university $(<3.2 \mathrm{~kg} ; 3.2-6.4 \mathrm{~kg} ; 6.4-12.7 \mathrm{~kg} ;>12.7 \mathrm{~kg})$.

Data from 247 current student members who reported to have gained weight whilst at university were entered into the analysis. Of these students, $99 \%$ were female and $73 \%$ were between $18 \& 25$ years of age. The majority $(67 \%)$ of students reported to have gained between $3.2 \mathrm{~kg}$ and $12.7 \mathrm{~kg}$ during their time at university; $24 \%$ reported to have gained over $12.7 \mathrm{~kg}$. The majority ( $65 \%)$ of students reported gaining between $3.2 \mathrm{~kg}$ and $12.7 \mathrm{~kg}$ during their first year. Before joining Slimming World, approximately half of all students consumed at least three ready meals or convenience foods each week; students reporting greatest weight gain reported most frequent consumption of these foods $\left(\chi^{2}=32 \cdot 0 ; \mathrm{df}=9 ; p<0 \cdot 001\right)$. Also, $56 \%$ of students reported that they consumed at least 'a few' takeaways or fast food meals each week; students reporting greatest weight gain also reported most frequent consumption of these foods $\chi^{2}=$ $11 \cdot 3 ; \mathrm{df}=3 ; p=0 \cdot 009)$. Only $20 \%$ of students consumed fruit and vegetables daily and students reporting greatest weight gain reported least frequent consumption $\left(\chi^{2}=21 \cdot 2 ; \mathrm{df}=9 ; p=0 \cdot 01\right)$. Students reporting weight gain of $3 \cdot 2-6 \cdot 4 \mathrm{~kg}$ were more likely to consume alcohol on one or two nights of the week $\left(\chi^{2}=13 \cdot 1 ; \mathrm{df}=6 ; p=0.041\right)$, however over one third of all students reported drinking alcohol on at least three nights of the week. Students reporting extremes of weight gain $(<3.2 \mathrm{~kg}$ and $>12.7 \mathrm{~kg})$ were more likely to attribute a lack of 'knowledge or skills to cook healthily' to their weight gain $\left(\chi^{2}=11.7 ; \mathrm{df}=3 ; p=0.009\right)$. Only $15 \%$ of students reported levels of physical activity that approached government guidelines. Counter-intuitively, however, students who reported the greatest weight gain at university reported greater levels of physical activity $\left(\chi^{2}=20 \cdot 1 ; \mathrm{df}=6 ; p=0.003\right)$.

The range of self-reported weight gain among this student sample was large. Consumption of takeaways and fast food, ready meals and convenience foods, and fruit and vegetables were associated with weight gain. Further, prospective studies to confirm these associations are now needed.

1. Cockman C, O'Reilly J \& Mellor D (2013) Proc Nutr Soc 72, E208.

2. Finlayson G, Cecil J, Higgs S, et al. (2012) Appetite 58, 1091-8. 